http://dx.doi.org/10.5007/1981-1322.2014v9nespp57

\title{
Modelagem Matemática nos Anos Iniciais: pesquisas, práticas e formação de professores
}

\author{
Mathematical Modelling in Elementary School: research, practices and formation of \\ teachers
}

\author{
Elizabeth Gomes Souza ${ }^{1}$ \\ elizabethmathematics@gmail.com
}

Ana Virgínia de Almeida Luna ${ }^{2}$

andrluna@uol.com.br

\begin{abstract}
Resumo
Este artigo tem como objetivo propor algumas ações de formação em modelagem, específicas para professores dos anos iniciais da educação básica, e delinear temáticas de pesquisas emergentes, a partir de um panorama de pesquisas que tematizam a modelagem matemática nessa fase da escolaridade. Para isso, apresentamos práticas de modelagem legitimadas na literatura e discutimos estudos que circulam no campo da formação matemática dos professores dos anos iniciais. Por fim, apontamos temas de pesquisas emergentes dessas análises, que podem contribuir para a consolidação de pesquisas relativas à formação de professores em modelagem dos anos iniciais e para a compreensão da peculiaridade da prática de modelagem nesta etapa da educação básica.
\end{abstract}

Palavras-chave: Modelagem Matemática. Pesquisas. Práticas. Formação de professores dos anos iniciais.

\begin{abstract}
This article aims to propose some formation actions in mathematical modelling for teachers of early years of education system as well as outline topics of research raised from the review of studies that analyze mathematical modeling in elementary school. To do so, we present modelling practices that have been legitimized in literature. We have also discussed researches that circulate in the field of Mathematics Teacher Education in the early years and outlined some formation actions in mathematical modelling. Finally, we point out some research topics that have raised from those analyzes that can contribute to the consolidation of research on formation of teachers of early years in mathematical modeling and to understand the peculiarity of the modelling practice in that education level.
\end{abstract}

Keywords: Mathematical Modeling. Research. Practices. Formation of elementary school teachers.

\footnotetext{
${ }^{1}$ Doutora em Ensino, Filosofia e História das Ciências pela Universidade Federal da Bahia e Universidade Estadual de Feira de Santana. Professora Adjunta do Instituto de Educação Matemática e Científica da Universidade Federal do Pará (UFPA) e do Programa de Pós-Graduação em Educação Matemática e Científica (UFPA). Integrante do Grupo de Estudos em Modelagem Matemática (GEMM/UFPA). Endereço para correspondência: Rua Augusto Corrêa, 01 - Guamá. CEP: 66075-110. Caixa postal 479. Belém-Pa.

${ }^{2}$ Doutora em Ensino, Filosofia e História das Ciências pela Universidade Federal da Bahia e Universidade Estadual de Feira de Santana. Professora Adjunta da Universidade Estadual de Feira de Santana (UEFS). Coordena o Núcleo de Estudos em Educação Matemática de Feira de Santana (NEEMFS/UEFS) e a Sociedade Brasileira de Educação Matemática- Regional Bahia. Membro do Grupo de pesquisa de Ensino de Ciências e Matemática (ENCIMA/UFBA). Endereço para correspondência. Campus Universitário, Avenida Transnordestina s/n- Novo Horizonte. CEP: 44031-460. Feira de Santana-Ba.
} 


\section{Introdução}

Coexistem, na literatura sobre modelagem ${ }^{3}$ na perspectiva da Educação Matemática, diferentes definições, a saber: estratégia de ensino, abordagem pedagógica, processo de obtenção de modelos matemáticos, metodologia de ensino, ambiente de modelagem, entre outros. De maneira geral, modelagem pode ser compreendida como a abordagem de situações-problema do dia a dia, por meio de conceitos e procedimentos matemáticos.

A multiplicidade de modos de conceber modelagem e, consequentemente, modos de implementá-la em sala de aula é representativa da consolidação crescente desse campo na perspectiva da Educação Matemática. Tal fato pode ser constatado pela realização de eventos regionais, nacionais e internacionais, pela publicação de livros específicos, pela elaboração de teses e dissertações, entre outros.

Todavia, o quantitativo de pesquisas produzidas no campo da modelagem na perspectiva da Educação Matemática ainda não possui ressonância direta nas práticas pedagógicas dos professores (BICUDO; KLÜBER, 2011; BLUM et al., 2002; SILVEIRA, 2007), pois ainda não são representativas as inserções efetivas da modelagem nas salas de aula.

Os fatores relacionados a essa lacuna são inúmeros, e um deles reside na dimensão relativa à formação do professor (BARBOSA, 2004; BASSANEZI, 2002; BLUM et al., 2002; CALDEIRA, 2007). Dessa maneira, pesquisas que se debrucem sobre a formação de professores podem contribuir para compreensão dos processos de formação e da prática do professor, constituída a partir de tais processos.

Bicudo e Klüber (2011), em um estudo meta-analítico sobre as pesquisas em modelagem publicadas no $3^{\circ}$ Seminário Internacional de Pesquisa em Educação Matemática (SIPEM), ocorrido em 2006, apontaram para a ausência de pesquisas de modelagem que tematizassem e/ou implementassem modelagem nos anos iniciais do ensino fundamental. Também Silva e Klüber (2012) destacaram que esta etapa de ensino raramente integra o lócus de pesquisa ou o foco de análise em dissertações de mestrado e tese de doutorado que elegem o campo de pesquisa de modelagem na perspectiva da educação matemática.

Diante disso, o presente artigo se configura como teórico, com o objetivo apresentar um conjunto de ações de formação referente à modelagem e a temáticas de pesquisas emergentes,

\footnotetext{
${ }^{3}$ Por vezes, iremos utilizar apenas a palavra “modelagem”, quando nos referirmos à modelagem matemática na perspectiva da educação matemática.
} 
a partir da análise do que nos informa o panorama de pesquisas em modelagem nos anos iniciais. Inspiradas em Silva (2007), adotamos a expressão "ações de formação" para designar propostas/questões de formação, em caráter sugestivo, que podem ser inseridas e debatidas na pauta de cursos de formação de professores em modelagem em diferentes configurações: cursos de curta duração, cursos de formação inicial, cursos de formação continuada, entre outros.

\section{Modelagem nos anos iniciais do período de escolarização: um panorama de pesquisas}

Nesta seção, apresentaremos um panorama qualitativo e quantitativo das pesquisas presentes na literatura brasileira sobre modelagem nos anos iniciais do período de escolarização. Escolhemos, para sistematizar as informações obtidas, análises dos seguintes itens: natureza, filiação, objetivo, atividade de modelagem, ano de implementação, forma de desenvolvimento da atividade, concepção de modelagem adotada e/ ou teoria, considerações finais realizadas. Trataremos alguns desses itens com maior ênfase.

As informações analisadas foram extraídas de fontes diversas, julgadas pelas autoras deste texto como representativas de pesquisas sobre modelagem na perspectiva da educação matemática. São elas: Conferência Nacional de Modelagem Matemática na Educação Matemática (CNMEM), edições de 2007, 2009, 2011 e 2013; Encontro Nacional de Educação Matemática (ENEM), edições de 2010 e 2013; Seminário Internacional de Pesquisa em Educação Matemática (SIPEM), edições de 2009 e 2012; artigos publicados em revistas ${ }^{4}$; teses e/ou dissertações e livros 5 .

Nos anais da CNMEM realizada em 2007, do total de 57 trabalhos, apenas um descreve experiências de modelagem nos anos iniciais. Trata-se de uma comunicação científica, cujo objetivo foi compreender as interações discursivas em tarefas de modelagem entre a professora e as crianças da quarta série (atual quinto ano) do ensino fundamental. As autoras do texto, Luna e Alves (2007), informaram que o tema "anorexia" foi escolhido por estar

\footnotetext{
${ }^{4}$ Escolhemos analisar artigos sobre modelagem nos anos iniciais publicados em revistas referenciadas na tabela de Periódicos Capes.

${ }^{5}$ Os livros analisados foram: Modelagem matemática na educação matemática brasileira: pesquisas e práticas educacionais (BARBOSA et al., 2007) e Práticas de modelagem matemática na educação matemática (ALMEIDA et al., 2011), ambos organizados pela coordenação do Grupo de Trabalho de Modelagem, filiado à Sociedade Brasileira de Educação Matemática (SBEM).
} 
relacionado ao projeto saúde desenvolvido na escola durante aquele período, além da intensa divulgação televisiva sobre a temática.

Também nos anais da CNMEM de 2009, do total de 67 trabalhos, o relato de experiência de Dias e Chaves (2009) é o único sobre modelagem nos anos iniciais. Ele descreve o desenvolvimento do tema "Pirataria e qualidade de vida" com crianças da terceira série (quarto ano), escolhido após debate entre elas em uma roda de conversa sobre brincadeiras e lazer infantil.

Souza, Santiago e Luna (2011) enfatizaram que as tarefas de modelagem nos anos iniciais propiciam uma abordagem transdisciplinar dos temas adotados. Elas apresentam alguns desdobramentos didáticos sobre o tema "trânsito", realizados com crianças do quinto ano do ensino fundamental. O trabalho se configura como comunicação científica única sobre os anos iniciais e modelagem, presente nos anais da CNMEM de 2011, em que o total foi de 65 trabalhos, entre relatos de experiência e comunicações científicas.

A CNMEM ocorrida em 2013 contou com dois trabalhos específicos sobre modelagem nos anos iniciais, do total de 63. Rehfeldf et al. (2013) ilustram, em um relato de experiência, algumas tarefas de modelagem elaboradas por professores dos anos iniciais. O segundo trabalho (LUNA; SANTIAGO; ANDRADE, 2013), uma comunicação científica, teve como objetivo identificar aspectos considerados na organização de tarefas de modelagem nos anos iniciais. As autoras explicitam questões adotadas pelas professoras para o planejamento e o desenvolvimento de tarefas de modelagem em uma turma do quinto ano do ensino fundamental.

O trabalho de Luna, Souza e Lima (2012) é o único presente nas edições do SIPEM entre os anos de 2006 a 2012. O artigo publicado nos anais do V SIPEM visou analisar a produção de textos matemáticos pelas crianças do quinto ano do ensino fundamental, a partir de debates sobre o tema "internet e pirataria".

Dois relatos de experiência podem ser encontrados nos anais do ENEM realizado em 2010. Santiago, Santos e Luna (2010) trataram o tema "políticas públicas e educação sexual" em uma turma do quinto ano do ensino fundamental. As autoras destacaram que a tarefa possibilitou o ensino de diversos conteúdos matemáticos escolares. Lopes e Azevedo (2010), em um relato de experiência no ENEM, trataram dos desafios vivenciados por elas na propositura e no decorrer da vivência de uma atividade de modelagem. As autoras não citaram 
o nível de escolaridade das crianças, mas destacaram dificuldades ao ensinar conteúdos não programados para a etapa de ensino. Não encontramos trabalhos sobre o tema nos anais do ENEM de 2013.

A produção de artigos científicos divulgados em periódicos da área repete a escassez identificada nos anais de eventos citados acima. Todavia, a primeira abordagem do tema "modelagem" nos anos iniciais ocorreu via periódico, em 1994, com o artigo de autoria de Dionísio Burak (1994). Ele aponta indicadores para professores e pesquisadores quanto à implementação da modelagem na educação básica, de maneira geral; contudo, identifica características quando essa implementação ocorre nos anos iniciais. Evidencia, por exemplo, a importância de as tarefas de modelagem nessa etapa iniciarem a partir dos interesses das crianças.

O trabalho de Luna, Souza e Santiago (2009) explicita as possibilidades de tarefas de modelagem propiciarem que as crianças desenvolvam análises críticas de argumentos pautados em matemática. A pesquisa foi realizada com crianças do quinto ano sobre o tema "a construção de cisternas no semiárido baiano".

No artigo de Tortola e Almeida (2013), é possível identificar correlações entre a natureza de tarefas de modelagem e a estrutura de questões relativas aos testes da Prova Brasil. Os autores analisaram as respostas escritas de crianças do quinto ano que haviam anteriormente vivenciado tarefas de modelagem e identificaram relações entre as diferentes formas de desenvolvê-las matematicamente.

Já o artigo de Silva e Klüber (2012) teve como objetivo identificar em que níveis de ensino estão focadas as pesquisas em modelagem na educação matemática. Os autores analisaram resumos de teses e dissertações, presentes no banco de dados Capes no período de 1987 a 2010, e constataram a ausência de pesquisas dessa natureza que tivessem abordado modelagem nos anos iniciais.

Todavia, em 2012, duas dissertações de mestrado concluídas ${ }^{6}$ tematizaram, especificamente, a implementação da modelagem nos anos iniciais. A dissertação de Tortola (2012) versa sobre a realização de tarefas de modelagem com crianças do quarto ano do ensino fundamental, com

\footnotetext{
${ }^{6}$ Não identificamos, até o momento, no banco de dissertações e teses da Capes, teses de doutorado que abordem, especificamente, a realização de tarefas de modelagem nos anos iniciais. Também não tivemos acesso à tese desenvolvida por Burak (1992), que traz alguns elementos sobre modelagem nos anos iniciais, embora não como foco de pesquisa.
} 
objetivo de identificar a forma como as crianças produzem modelos matemáticos e qual o papel da linguagem nessa produção.

A dissertação de Kaviatkovski (2012) aborda a análise das respostas dadas por professores em formação continuada, participantes de dois cursos de curta duração sobre modelagem nos anos iniciais. A pesquisadora analisou, codificou e categorizou as respostas dos professores em distintas dimensões: currículo, formação do professor, crenças e mitos, entendimentos de modelagem, organização escolar, entre outros.

No que se refere à produção bibliográfica sobre modelagem na perspectiva da educação matemática nos anos iniciais, o estudo de Caldeira (2007) se constitui como único. O autor trata da realização de atividades de modelagem com crianças da $3^{\mathrm{a}}$ e $4^{\mathrm{a}}$ séries $\left(4^{\mathrm{o}}\right.$ e $5^{\mathrm{o}}$ ano) do ensino fundamental em uma escola da zona rural e destaca que a modelagem pode promover relações entre os saberes cotidianos das crianças e os saberes escolares sistematizados.

\section{Práticas de modelagem nos anos iniciais}

As análises das pesquisas citadas acima nos permitiram identificar algumas características a respeito da especificidade da prática de modelagem nos anos iniciais, e uma delas corresponde à escolha do tema.

Predominantemente, a escolha do tema foi realizada pelos professores; todavia, os encaminhamentos específicos se definiram no decorrer da pesquisa das crianças sobre o tema, ou seja, a pesquisa realizada por elas direcionou a especificidade de questões e conteúdos disciplinares tratados. Portanto, não ocorreu um direcionamento prévio a respeito de quais conteúdos abordar.

Além disso, a implementação da tarefa de modelagem foi relacionada à prática de ensino peculiar aos professores dos anos iniciais, como a roda de conversa, as feiras escolares e a elaboração de relatórios. Esse fato pode ser indicativo de que as atividades de modelagem propostas pelos professores dos anos iniciais se moldam às práticas de ensino específicas dos professores deste nível.

Também nas pesquisas analisadas na seção anterior foi identificada a busca de um especialista para informar às crianças dados relevantes a respeito do tema a ser explorado. São exemplos: a presença de um fisiologista na escola para tratar sobre anorexia e a de um geógrafo para 
esclarecer as crianças a respeito da construção de cisternas, citadas por Luna e Alves (2007) e Luna, Souza e Santiago (2009), respectivamente. Neste segundo trabalho, destacamos a maneira transdisciplinar pela qual a professora abordou o tema, no que se refere a sua abrangência dos diferentes conteúdos disciplinares (ciências, geografia, história, entre outros) e não disciplinares (direitos autorais, políticas públicas e impostos).

Outro item destacado nas pesquisas corresponde à peculiaridade da produção matemática infantil em atividades de modelagem nos anos iniciais: é frequente a elaboração de desenhos, paralelamente à produção escrita e oral das crianças, referente à temática abordada, conforme destaca Tortola (2012).

As pesquisas sobre modelagem nos anos iniciais se concentram em artigos que relatam práticas e descrevem-nas em termos de suas potencialidades para o ensino da matemática nesse nível. A maioria foi realizada nos últimos anos do ensino fundamental ( $4^{\circ}$ e $5^{\circ}$ ano) e está documentada em anais de eventos da área da educação matemática.

São raras as pesquisas que tratam e analisam essas práticas à luz de conceitos teóricos específicos. Há relatos de experiências sobre os desafios dos professores dos anos iniciais quando desenvolvem modelagem, mas não dispomos de uma reflexão teórica específica que enviese ela, por exemplo.

O panorama de pesquisas realizado neste texto nos informou o ínfimo quantitativo de pesquisas realizadas sobre modelagem nos anos iniciais ou que adotam essa etapa de ensino como contexto de sua implementação. Silva e Klüber (2012) apontam que essa ausência pode ser justificada pelo debate pouco frequente a respeito da modelagem em cursos de pedagogia, haja vista serem esses cursos o campo de formação de professores que atuam nos anos iniciais do ensino fundamental.

Todavia, a inserção da modelagem em cursos de formação inicial ou continuada de professores dos anos iniciais necessita de análises a respeito da natureza da formação que se propõe ou que se pode propor para professores que atuam nessa específica etapa de ensino. Quais dimensões podemos abordar nos cursos de formação de professores em modelagem para professores dos anos iniciais? Que ações de formação poderiam orientar a formação de professores para essa etapa de ensino? 
As respostas para essas questões são diversas e não definitivas, todavia necessárias para pensarmos a formação de professores dos anos iniciais, com vistas a proporcionar-lhes a possibilidade de implementar atividades de modelagem nesta etapa da educação básica.

A fim de elaborarmos propostas específicas para a formação de professores dos anos iniciais, analisamos e identificamos o que nos apontam as pesquisas sobre formação de professores dos anos iniciais em matemática.

\section{Pesquisas sobre a formação matemática dos professores dos anos iniciais}

Curi e Pires (2008) elaboraram pesquisas com o propósito de investigar a forma como um grupo de professores polivalentes desenvolvia o ensino de geometria com seus alunos e quais mudanças aconteceram na prática desses professores, durante e após sua participação no processo de formação com foco no ensino de geometria. As autoras destacaram que a formação de professores dos anos iniciais precisa de maiores aprofundamentos referentes à ampliação da formação matemática dos professores.

Para Jaramillo, Freitas e Nacarato (2005), os debates a respeito da formação de professores dos anos iniciais devem agendar análises profundas que abarquem mudanças nas concepções de formação profissional. As autoras apontam para propostas formativas que adotem os conhecimentos dos professores advindos das suas experiências em uma perspectiva colaborativa entre o professor e o pesquisador.

Essas parcerias podem gerar um ambiente propício para estudos, discussões e análises de práticas desenvolvidas em situação real, considerando a complexidade do espaço escolar. Para tanto, as autoras sugerem que as propostas formativas estimulem a elaboração, pelos professores, de narrativas a respeito de suas práticas, a fim de que tais relatos sejam fonte de reflexão e parâmetro para a elaboração de propostas de formação de professores dos anos iniciais.

Para Nacarato, Mengali e Passos (2009), a dimensão formativa de professores dos anos iniciais também deve inserir discussões relativas às mudanças de concepções dos docentes em relação à visão exclusivamente utilitarista e reducionista de matemática. Segundo as autoras, os professores dos anos iniciais, por vezes, compartilham crenças sobre a matemática que dificultam a inserção de novas formas de concebê-la. 
No que diz respeito a ações de professores, no âmbito da sala de aula, que podem ter repercussão em espaços de formação, é possível considerar a proposta apresentada por Borba (2008), segundo a qual o professor dos anos iniciais desenvolve pesquisas no espaço de sala de aula em que atua, investigando, por exemplo, a natureza das dificuldades dos alunos em relação aos diferentes conteúdos a serem contemplados nos anos iniciais ou a possíveis intervenções docentes para possibilitar o avanço dos alunos. Nesse sentido, a autora desenvolve a proposta de atuação do professor como pesquisador.

Tendo em vista a escassez de pesquisas sobre modelagem nos anos iniciais, tivemos como objetivo elaborar ações de formação de professores em modelagem para essa etapa de ensino. A partir de demandas apontadas em pesquisas sobre modelagem nos anos iniciais e das características das práticas de modelagem, delineamos um conjunto de ações de formação de professores em modelagem, em caráter sugestivo.

\section{Ações de formação em modelagem para professores dos anos iniciais}

Conforme constatamos no panorama de pesquisas apresentado neste artigo, a formação de professores dos anos iniciais em modelagem não tem sido predominantemente tematizada nas pesquisas sobre modelagem nos anos iniciais. Além disso, a inserção da modelagem na formação de professores dos anos iniciais tem se limitado a cursos de curta duração, conforme podemos identificar em Burak (1994), Kaviatkovski (2012) e Luna (2012) ${ }^{7}$.

Inicialmente, a ação de formação de professores em modelagem sugerida por nós corresponde à ênfase que pode ser dada no campo de formação, à natureza social da matemática. Em modelagem, os temas do dia a dia eleitos para análise são férteis para o debate estimulado pelo professor a respeito do papel da matemática e de suas relações com demandas e interesses sociais, políticos e econômicos compartilhados na sociedade.

Outra ação relevante de formação em modelagem em cursos de formação de professores em modelagem se refere à ampliação de repertório matemático dos professores dos anos iniciais. Curi (2005) e Nacarato, Mengali e Passos (2009) destacam que professores dos anos iniciais tendem a identificar, nos problemas matemáticos, apenas estratégias que contemplem as

\footnotetext{
${ }^{7}$ Na pesquisa realizada por Luna (2012), o espaço de formação em modelagem foi constituído por professores de diferentes etapas de ensino; entre eles, professores dos anos iniciais.
} 
operações básicas, sem apontar para outros possíveis conteúdos matemáticos que podem estar relacionados.

Sugerimos que o professor formador inclua, na proposta de formação de professores dos anos iniciais, análises e estudos referentes aos blocos de conteúdos sugeridos nos Parâmetros Curriculares Nacionais (BRASIL, 1997); aos anos iniciais; e aos demais anos do ensino fundamental, com vistas a destituir o que Nacarato, Mengali e Passos (2009) denominam de "visão reducionista de matemática dos professores dos anos iniciais".

Em cursos de formação de professores em modelagem ${ }^{8}$, essa proposta pode ser implementada, quando, na abordagem matemática de situações-problema do dia a dia, o formador, por exemplo, estimular a identificação, pelos professores, de diferentes blocos de conteúdos que podem ser mobilizados para resolver as situações-problema.

Todavia, a abordagem matemática do tema do dia a dia não deve ser concebida como foco principal do desenvolvimento da atividade de modelagem, nem como seu ponto de partida. Nessa direção, outra ação de formação que julgamos relevante a ser considerada na delimitação de propostas de formação de professores em modelagem para os anos iniciais corresponde à articulação do tema do dia a dia de forma equânime a outros domínios, disciplinares ou não.

Além disso, os professores dos anos iniciais possuem práticas de ensino peculiares, como rodas de conversa, leitura de textos literários, contação de histórias, entre outros. Por conta disso, entendemos que as ações de formação em modelagem voltadas para professores dos anos iniciais devem contemplar essas especificidades, no que tange à configuração da prática de modelagem.

$\mathrm{O}$ fato de os professores dos anos iniciais implementarem atividades de modelagem de maneira relacionada às ações que desenvolvem em suas práticas de ensino corrobora a indicação de Jaramillo, Freitas e Nacarato (2005) a respeito da importância de inserir, tematizar e configurar cursos de formação de professores nos anos iniciais, a partir de práticas de ensino que os professores já vivenciam ou que são peculiares a sua prática.

\footnotetext{
${ }^{8}$ Entendemos cursos de formação de professores em modelagem como aqueles que explicitem tratar da formação de professores para a implementação da modelagem nos anos iniciais. Eles podem se desenvolver por meio de disciplinas em cursos de extensão, cursos de graduação, cursos de pós-graduação, entre outros. Ou, ainda, no interior de outras disciplinas, como práticas de ensino e estágios supervisionados.
} 
Tortola (2012) relata que as crianças do quarto ano do ensino fundamental elaboraram diferentes registros matemáticos (verbal, escrito, tabular, desenhos, entre outros), referentes às situações-problema estudadas. Esse fato reitera que as produções elaboradas pelas crianças são configuradas pelas especificidades dos registros que elas mesmas podem produzir e devem ser tematizadas nas ações de formação, o que pode ocorrer por meio de estudos específicos sobre os tipos de registros comumente realizados pelas crianças.

A produção de narrativas pelos próprios professores é uma ação formativa indicada por Nacarato, Mengali e Passos (2009) como importante em cursos de formação de professores dos anos iniciais. Essa proposta formativa em modelagem pode ser estruturada a partir de relatos de experiências de professores que já desenvolveram atividades de modelagem em suas salas de aula.

Oliveira (2010) e Oliveira e Barbosa (2011) destacaram que os professores especialistas vivenciam tensões quando desenvolvem atividades de modelagem em sala de aula. Dessa maneira, entendemos ser relevante, nas ações de formação dos professores dos anos iniciais em modelagem, a tematização dos dilemas, das incertezas e inseguranças que os professores dos anos iniciais vivenciaram ou que são citados por outros professores.

As vivências de professores dos anos iniciais no desenvolvimento de atividades de modelagem, todavia, não devem ser vistas como um momento individual de constituição de práticas. Barbosa (2001) e Araújo et al. (2011) sugerem que a prática do professor seja realizada em uma perspectiva colaborativa entre professor cursista e formador, o que nos indica que a prática de modelagem seja fruto de uma elaboração coletiva, e suas reflexões sejam fontes de conhecimentos tanto para o professor como para o formador.

Nacarato (2013, p. 4) aponta, além disso, outra questão relevante: a necessidade de considerar a escola como lócus privilegiado de formação docente, tendo como concepção de desenvolvimento profissional do professor a de formação "sentada na escola" .

Essa ideia imprime o entendimento de que as ações de formação em modelagem devem se constituir como políticas de formação de professores, em um caráter permanente e contínuo,

\footnotetext{
${ }^{9}$ A expressão "formação sentada na escola", usada por Nacarato (2013), tem inspiração em Canário (2000), que utiliza o termo para enfatizar a necessidade de tematizar questões relativas à prática do professor no seu contexto de ensino.
} 
tendo questões relativas à escola e na escola como fonte de permanente de construção e reconstrução de propostas formativas profissionais.

Por fim, as sugestões apontadas nesta seção como ações de formação de professores dos anos iniciais em modelagem não devem ser vistas como lineares, prescritivas e únicas. Nessa direção, concordamos com Araújo et al. (2011), que enfatizam a importância de a proposta de formação ser constituída antes e durante o curso de formação.

Os autores sugerem que questões propostas pelos próprios professores cursistas, com base nas suas sugestões a respeito de quais demandas à sua formação eles julgam importantes de serem discutidas em cursos de formação em modelagem, sejam acrescidas às previamente elaboradas pelo formador.

\section{Novos rumos... Temáticas de pesquisa para a formação de professores dos anos iniciais em modelagem}

Este artigo teve como objetivo propor ações de formação de professores dos anos iniciais em modelagem e temáticas de pesquisas, a partir do mapeamento de pesquisas relativas à modelagem nos anos iniciais do período de escolarização.

Diante disso, esta seção conclusiva visa apontar algumas temáticas de investigação que podem compor a agenda de pesquisas em modelagem, com vistas a ampliar e viabilizar a compreensão sobre a prática de modelagem de professores dos anos iniciais do ensino fundamental, os professores polivalentes.

Tendo em vista que a prática dos professores dos anos iniciais em modelagem indica que eles adotam, para a abordagem do tema, encaminhamentos não previamente estipulados, pesquisas podem ser realizadas, para identificar quais textos ${ }^{10}$ do campo de formação os professores usam em sua prática de sala de aula.

Também destacamos a importância de pesquisas que identifiquem o modo como os professores polivalentes abordam os conteúdos disciplinares e não disciplinares de maneira equânime em tarefas de modelagem. Essa pesquisa pode ser colaborativa, envolvendo diferentes grupos de pesquisas do País. Dessa forma, inferimos que seria possível termos uma

${ }^{10} \mathrm{O}$ texto aqui deve ser entendido, como a comunicação oral, escrita, gestual, visual e espacial produzida pelos indivíduos (BERNSTEIN, 2003). 
visão mais ampla em relação ao desenvolvimento desse ambiente em práticas pedagógicas nos anos iniciais.

O terceiro tema que sugerimos é o desenvolvimento de uma pesquisa inspirada em Oliveira e Barbosa (2011), com o propósito de identificar tensões específicas vivenciadas por professores dos anos iniciais durante o desenvolvimento de atividades de modelagem. Lopes e Azevedo (2010) indicam, por exemplo, desafios relativos à abordagem de conteúdos que extrapolam os previstos para os cinco anos do período de escolarização.

Nesse âmbito, apontamos para pesquisas que tematizem o espaço de formação, no que se refere às ações de formação de professores em modelagem. Como os formadores poderão ampliar o repertório matemático dos professores em formação no interior dos cursos de formação em modelagem? Ou ainda, a formação compreenderá os conhecimentos didáticos e pedagógicos dos conteúdos, ou seja, o ensino dos conteúdos disciplinares às crianças?

Além disso, outras questões de pesquisa devem tematizar a formação do formador de professores dos anos iniciais em modelagem. Se a prática de modelagem dos professores dos anos iniciais é marcadamente transdisciplinar, pois o professor é polivalente, de que maneira o formador que possui predominantemente uma formação especialista orientará uma abordagem transdisciplinar e/ou não disciplinar equânime do tema em sala de aula pelo professor cursista?

A sexta temática de pesquisa que pode ser adotada na formação de professores dos anos iniciais se refere a conceber o professor como pesquisador de sua própria prática, conforme nos sugerem Borba (2008) e Nacarato (2013). Diante disso, poderíamos ter pesquisas em relação à formação de professores dos anos iniciais em modelagem, cujas demandas seriam constituídas pelo professor e pelo pesquisador na escola, oriundas das permanentes, contínuas e colaborativas reflexões sobre a prática.

Há ainda outros temas que precisam ser agendados em pesquisas sobre modelagem nos anos iniciais, como a ética de pesquisas com crianças. Isso porque, embora sob a tutela de adultos e responsáveis, as crianças precisam ser ouvidas a respeito da realização da pesquisa e da aceitação de sua participação nelas.

A crescente consolidação do campo de pesquisa em modelagem na perspectiva da educação matemática sinaliza a relevância de sua inserção efetiva no contexto escolar. Discutir, 
elaborar, propor e reformular propostas de formação e temáticas de pesquisa em modelagem para professores dos anos iniciais pode contribuir para a implementação da modelagem neste e nas demais etapas de ensino da educação básica.

\section{Referências}

ALMEIDA, L. M.W. et al. (Org.). Práticas de modelagem matemática na educação matemática. Londrina: Eduel, 2011.

ARAÚJO, J. L. et al. A disciplina de modelagem matemática na educação matemática: motivos dos alunos-professores na constituição de um espaço de formação. In: CONFERÊNCIA NACIONAL DE MODELAGEM MATEMÁTICA NA PERSPECTIVA DA EDUCAÇÃO MATEMÁTICA, 7., 2011, Belém. Anais... Belém, 2011. 1 CD-ROM

ALMEIDA, L. M.W. et al. (Org.). Práticas de modelagem matemática na educação matemática. Londrina: Eduel, 2011.

BARBOSA, J. C.et al.(Org.). Modelagem Matemática na Educação Matemática Brasileira: pesquisas e práticas educacionais. Recife: SBEM, 2007.

BARBOSA, J. C. As relações dos professores com a Modelagem Matemática. In: ENCONTRO NACIONAL DE EDUCAÇÃO MATEMÁTICA, 8., 2004, Recife. Anais... Recife: SBEM, 2004. 1 CD-ROM.

BARBOSA, J. C. Modelagem matemática e os professores: a questão da formação. Bolema. Boletim de Educação Matemática, Rio Claro, n. 15, p. 5-23, 2001.

BASSANEZI, R. C. Ensino-aprendizagem com Modelagem Matemática.São Paulo: Contexto, 2002.

BERNSTEIN, B. Class, codes and control: the structuring of pedagogic discourse. Londres: Routledge - Taylor \& Francis Group, 2003.

BICUDO, M. A.V; KLÜBER, T. E. Pesquisa em modelagem matemática no Brasil: a caminho de uma metacompreensão. Cadernos de Pesquisa, São Paulo, v. 34, n. 144, 2011.

BLUM, W. et al. ICMI Study 14: applications and modelling in mathematics educationdiscussion document. Educational Studies in Mathematics, v. 51, 2002.

BORBA, R. E. S. R. Professores (as) das séries iniciais pesquisando a sala de aula de matemática: por que e como? In: GUIMARÃES; G.; BORBA, R. E. S. R. Reflexões sobre o ensino de matemática nos anos iniciais de escolarização. Recife: SBEM, 2008.

BRASIL. Ministério da Educação. Secretaria de Educação Fundamental. Parâmetros Curriculares Nacionais: Matemática $\left(1^{\circ}\right.$ e $2^{\circ}$ ciclos do ensino fundamental). v. 3. Brasília: MEC/SEF, 1997. 
BURAK, D. Critérios norteadores para a adoção da Modelagem Matemática no Ensino Fundamental e Secundário. Zetetiké, Campinas, v. 2, n. 2, 1994.

BURAK. D. Modelagem matemática: ações e interações no processo de ensinoaprendizagem. 1992. 459 p. Tese (Doutorado em Educação) - Faculdade de Educação, Universidade Estadual de Campinas, Campinas, 1992.

CALDEIRA, A. D. Etnomatemática e suas relações com a educação matemática na infância. In: BARBOSA, J. C.; CALDEIRA, A. D.; ARAÚJO, J. L. (Org.). Modelagem Matemática na Educação Matemática Brasileira: pesquisas e práticas educacionais. Recife: SBEM, 2007. p. 81- 98 .

CANÁRIO, R. A prática profissional na formação de professores. Inafop. Formação profissional de professores no ensino superior. Aveiro: Universidade de Aveiro, 2000.

CURI, E. A matemática e os professores dos anos iniciais. São Paulo: Musa, 2005.

CURI, E.; PIRES, C. M. C. Pesquisas sobre a formação do professor que ensina matemática por grupos de pesquisa de instituições paulistanas. Educação Matemática Pesquisa, São Paulo, v. 10, n. 1, p. 151-189, 2008. Disponível em: <http:// revistas.pucsp.br/index.php/emp/article/download/1655/1065>. Acesso em: 09 mar. 2014.

DIAS, J. L.; CHAVES, M. I. A. Diálogos com/na modelagem matemática nas séries iniciais. In: CONFERÊNCIA NACIONAL DE MODELAGEM MATEMÁTICA, 5., 2009, Londrina. Anais... Londrina, 2009. 1 CDROM.

JARAMILLO, D.; FREITAS, M. T. M.; NACARATO, A. M. Diversos caminhos de formação: apontando para outra cultura profissional do professor que ensina Matemática.

In: NACARATO, A. M.; LOPES, C. E. (Org.). Escritas e leituras na Educação

Matemática. Belo Horizonte, MG: Autêntica, 2005. p.163-190.

KAVIATKOVSKI, M. A. C. Modelagem Matemática como metodologia de ensino e aprendizagem nos anos iniciais do ensino fundamental. $136 \mathrm{f}$. Dissertação (Mestrado em Educação) - Universidade Estadual de Ponta Grossa, Ponta Grossa, 2012.

LOPES, R. P.; AZEVEDO, J. R. L. Modelagem matemática nas séries iniciais: os desafios do trabalho com a modelagem na sala de aula. In: ENCONTRO NACIONAL DE EDUCAÇÃO MATEMÁTICA, 10., 2010, Salvador. Anais ... Salvador, 2010. 1. CD-ROM.

LUNA, A. V. A. A modelagem matemática na formação continuada e a recontextualização pedagógica desse ambiente em salas de aula. 2012. 184f. Tese (Doutorado em Ensino, Filosofia e História das Ciências) - Instituto de Física/Departamento de Ciências Exatas, Universidade Federal da Bahia e Universidade Estadual de Feira de Santana, Salvador, 2012.

LUNA, A.V. A.; ALVES, J. Modelagem Matemática: as interações discursivas de crianças da $4^{\mathrm{a}}$ série a partir de um estudo sobre anorexia. In: CONFERÊNCIA NACIONAL DE 
MODELAGEM MATEMÁTICA, 5., 2007, Belo Horizonte. Anais... Ouro Preto, 2007. 1 CDROM.

LUNA, A.V. A.; SANTIAGO, A. R. C. M.; ANDRADE, M. C. A organização e o desenvolvimento de atividades de modelagem matemática por professores polivalentes In: CONFERÊNCIA NACIONAL DE MODELAGEM MATEMÁTICA, 8., 2013, Rio Grande do Sul. Anais... Santa Maria, 2013. 1 CD-ROM.

LUNA, A.V. A.; SOUZA, E. G.; LIMA, L. B. S. Textos sobre matemática em uma prática pedagógica no ambiente de modelagem nos anos iniciais. In: SEMINÁRIO INTERNACIONAL DE PESQUISA EM EDUCAÇÃO MATEMÁTICA, 5., 2012, Petropólis. Anais... Rio de Janeiro, 2012. 1 CD-ROM.

LUNA, A.V. A.; SOUZA, E. G.; SANTIAGO, A. R. C. M. A Modelagem Matemática nas séries iniciais: o gérmen da criticidade. ALEXANDRIA Revista de Educação em Ciência e Tecnologia, Santa Catarina, n. 2, p. 135-157, 2009.

NACARATO, A . M. Políticas públicas de formação do professor na educação básica: pesquisas, programas de formação. In: REUNIÃO ANUAL DA ANPED, 38., 2013, Brasília. Anais... Brasília: ANPED, 2013. 1 CD-ROM.

NACARATO, A. M.; MENGALI, B. L. S.; PASSOS, C. L. B. A matemática nos anos iniciais do ensino fundamental: tecendo fios do ensinar e do aprender. 1. ed. Belo Horizonte: Autêntica, 2009.

OLIVEIRA, A. M. P. Modelagem Matemática e as tensões nos discursos dos professores. 2010. 200p. Tese (Doutorado em Ensino, Filosofia e História das Ciências) - Instituto de Física/Departamento de Ciências Exatas, Universidade Federal da Bahia e Universidade Estadual de Feira de Santana, Salvador, 2010.

OLIVEIRA, A. M. P.; BARBOSA, J. C. Modelagem Matemática e situações de tensão na prática pedagógica dos professores. Bolema - Boletim de Educação Matemática - UNESP, Rio Claro, v. 24, p. 265-296, 2011.

REHFELDT, M. J. H. et al. A construção de propostas de modelagem matemática em cursos de formação continuada para professores os anos iniciais do ensino fundamental. In: CONFERÊNCIA NACIONAL DE MODELAGEM MATEMÁTICA NA PERSPECTIVA DA EDUCAÇÃO MATEMÁTICA, 7., 2011, Belém. Anais... Belém, 2011. 1 CD-ROM

SANTIAGO, A. R. M.; SANTOS, A. J. B.; LUNA, A. V. A. Modelagem matemática: um estudo sobre os métodos contraceptivos numa abordagem transdisciplinar. In: ENCONTRO NACIONAL DE EDUCAÇÃO MATEMÁTICA, 10., 2010, Salvador. Anais ... Salvador, 2010. 1. CD- ROM.

SILVA, D. Ações de modelagem para a formação inicial de professores de matemática. In: BARBOSA, J. C.; CALDEIRA, A.; ARAÚJO, J. L. (Org.). Modelagem matemática na Educação Brasileira: pesquisas e práticas educacionais. Recife: SBEM, 2007. p. 215-232. 
SILVA, S. S.; KLÜBER, E.T. Modelagem matemática nos anos iniciais do ensino fundamental: uma investigação imperativa. Revista Eletrônica de Educação - Programa de Pós-Graduação em Educação, Universidade Federal de São Carlos, Brasil, v. 6, n. 2, p.228249, nov. 2012.

SILVEIRA, E. Modelagem Matemática em Educação no Brasil: entendendo o universo de teses e dissertações. 197 p. Dissertação (Mestrado em Educação) - Universidade Federal do Paraná - UFPR, Curitiba, 2007.

SOUZA, L. B.; SANTIAGO; A. R. C. M.; LUNA, A.V A. Modelagem matemática nos anos iniciais: uma análise sobre o comportamento dos motoristas no trânsito numa perspectiva transdisciplinar. In: CONFERÊNCIA NACIONAL DE MODELAGEM MATEMÁTICA NA PERSPECTIVA DA EDUCAÇÃO MATEMÁTICA , 7., 2011, Belém. Anais... Belém, 2011. 1 CD-ROM.

TORTOLA, E. Os usos da linguagem em atividades de modelagem matemática nos anos iniciais do ensino fundamental. 168 p. Dissertação (Mestrado em Ensino de Ciências e Educação Matemática) - Universidade Estadual de Londrina, UEL, Londrina, 2012.

TORTOLA, E; ALMEIDA, L. M. W. Reflexões a respeito do uso da modelagem matemática em aulas nos anos iniciais do ensino fundamental. Revista Brasileira de Estudos Pedagógicos, Brasília, v. 94, n. 237, p. 619-642, 2013. 